\title{
Investigations of Polymers with Chromophore Units I. Synthesis and Properties of New Poly(ester-imide)s from 2,4-dihydroxy-4' -nitroazobenzene
}

\author{
Danuta SȨK, ${ }^{\dagger}$ Eugenia GrabieC, and Andrzej MiniewiCZ* \\ Centre of Polymer Chemistry, Polish Academy of Sciences, 34 M. Curie-Skłodowska St. 41-800 Zabrze, Poland \\ *Institute of Physical and Theoretical Chemistry, Wroclaw University of Technology, 50-370 Wroclaw, Poland
}

(Received February 21, 2003; Accepted August 5, 2003)

\begin{abstract}
A series of poly(ester-imide)s based on new azobenzene derivative 2,4-dihydroxy-4'-nitroazobenzene has been synthesized and characterised. An influence of macromolecules structures on the physical and chemical properties was investigated. The preliminary results of holographic recording in poly(ester-imide) foils are presented. KEY WORDS Poly(ester-imide)s / 2,4-Dihydroxy-4'-nitroazobenzene / Thermal Stability / Optical Properties /
\end{abstract}

In the last decade polymers containing chromophore units for example azo benzene groups have attracted attention because of a variety of potential applications in the field of optical data storage, nonlinear optics and holographic applications. ${ }^{1-8}$ The reversible photoisomerisation process of azo-groups is particularly interesting. The involved molecular reorientation can initiate photo-induced birefringence, dichroism and even

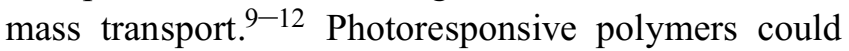
be prepared as Langmuir-Blodgett, ${ }^{13,14}$ spin-coated or casted films differing in thickness. Chromophore can be introduced into polymer's main chain or be bonded as a side group and eventually dispersed in a polymer matrix. Despite the fact that the last way is the easiest one the former ones offer much better stability of Nonlinear optical (NLO) properties. When a chromophore is attached to polymer as a side chain the optical properties of the polymer are mainly influenced by the structure of polymer backbone, the structure of the azo chromophore and the type of bonding of the chromophore to the main chain. High concentration of azo-groups in the polymer plays also a significant role.

In this work we have synthesized a series of poly(ester-imide)s from diesterdianhydride with azo groups in side chain and various diamines. The prepared materials will be tested for their use in dynamic holographic recording.

\section{EXPERIMENTAL}

\section{Materials Used in Synthesis}

4,4'-Diaminediphenylether (Merck) was crystallised from methanol, 1,2-phenylenediamine and 1,4-phenylenediamine were crystallised from methanol/water mixture in the presence of charcoal. 4,4'-Methylenedi-o-toluidine (Fluka) and 1,3phenylenediamine (Aldrich), 2,3,5,6-tetramethyl-1,4phenylenediamine (Aldrich), 4,4'-methylenedianiline (Aldrich), 3,3'5,5'-tetramethylbenzidine (Aldrich), 3,3'-dimetoxybenzidine (Aldrich), o-tolidine(Aldrich), 4,4'-diaminebiphenyl (Aldrich), 4,4'-methylene bis(2,6-dimethylaniline) (Aldrich), 4,4'-methylene bis(2,6-diethylaniline) (Aldrich), and 4,4'-(1,3phenylenedioxy)dianiline (Aldrich) were used without purification. Dimethylacetamide (DMA) (Aldrich) and dimethylformamide (DMF) (Aldrich) were distilled in the usual manner, 1-methyl-2-pyrrolidinone (NMP) (Aldrich) was dried with $4 \AA$ molecular sieves overnight.

\section{Synthesis of Monomers}

Synthesis of the Chromophore 2,4-Dihydroxy-4'nitroazobenzene (Azo-Diol) having the structure (Scheme 1) was synthesized according to the following procedure:

Flask with the mixture of $10 \mathrm{mmol}(1.44 \mathrm{~g})$ of $p$ nitroaniline in $2.7 \mathrm{~mL}$ of concentrated hydrochloric acid and $10 \mathrm{~mL}$ of water, was placed in an ice bath. To the cooled mixture a solution of $10 \mathrm{mmol}(0.7 \mathrm{~g})$ of sodium nitrite in $1.5 \mathrm{~mL}$ of water was added dropwise and the mixture was stirred at a temperature between

\footnotetext{
${ }^{\dagger}$ To whom correspondence should be addressed (Tel: +48-032-2716077, 2732214, Fax: +48-032-2712969, E-mail: danuta.sek@cchppan.zabrze.pl).
} 


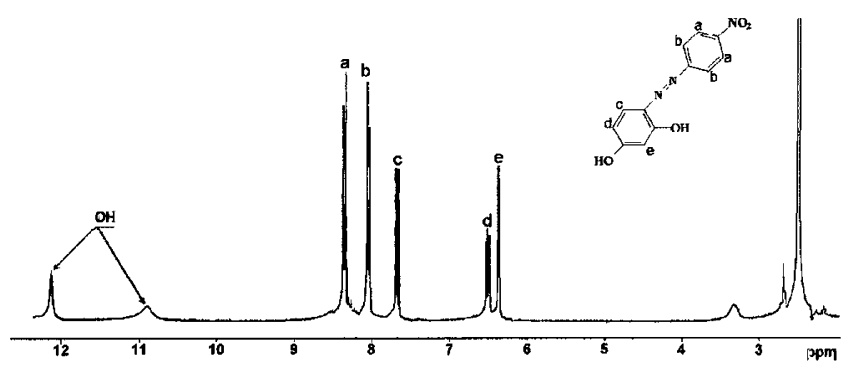

Figure 1. ${ }^{1} \mathrm{H}$ NMR (in DMSO- $d_{6}$ ) spectrum of the 2,4 dihydroxy-4'-azobenzene.

0 and $5{ }^{\circ} \mathrm{C}$ during $15 \mathrm{~min}$. Then it was poured slowly into a solution containing $10 \mathrm{mmol}(1.1 \mathrm{~g})$ of resorcinol in $8 \mathrm{~mL}$ of methanol. The mixture was stirred at a temperature between 0 and $5{ }^{\circ} \mathrm{C}$ for $30 \mathrm{~min}$ and then was neutralised with sodium acetate to $\mathrm{pH} 5-6$. After that temperature was raised to $20^{\circ} \mathrm{C}$ and the mixture was stirred for $1 \mathrm{~h}$. The product was filtered, washed with water and dried in vacuum at $70^{\circ} \mathrm{C}$. Yield: $85.1 \%$.

Elemental analysis: found (calc.); C $55.72(55.60) \%$, H $3.52(3.50) \%$, N 16.12 (16.21)\%; MS m/e = 259; Mp: 209-211 ${ }^{\circ} \mathrm{C}$ (dec) (differential scanning calorimetry, DSC). Proton nuclear magnetic resonance ( ${ }^{1} \mathrm{H}$ NMR) spectrum of Azo-Diol detected in DMSO- $d_{6}$ is shown in Figure 1.

In the ${ }^{1} \mathrm{H}$ NMR spectrum the following peaks (ppm) are observed: $10.8(\mathrm{~s},-\mathrm{OH}), 12.2(\mathrm{~s},-\mathrm{OH})$, (a) 8.368.33 (d, ArH, $2 \mathrm{H}$ ), (b) 8.06-8.03 (d, ArH, $2 \mathrm{H}$ ), (c) 7.69-7.66 (d, ArH, $1 \mathrm{H}),(\mathrm{d})$ 6.52-6.49 (m, ArH, $1 \mathrm{H})$, (e) 6.36-6.35 (d, ArH, $1 \mathrm{H})$.

The peaks at 10.8 and $12.2 \mathrm{ppm}$ are characteristic for hydrogen in phenol group. The phenomenon that protons of the two hydroxylic groups bonded with phenyl ring at different positions gives two peaks at ${ }^{1} \mathrm{H}$ NMR spectrum can be explained by possibility of creation of chelate bonds. Such chelate ring can be formed between nitrogen of azo group and hydrogen of $-\mathrm{OH}$ group placed in $o$-position. In this way two different signals of protons can be observed in the moiety of Azo-Diol.

In FT-IR (KBr) spectrum the following absorption bands were found and assigned as: $3280 \mathrm{~cm}^{-1}$ (O-H stretching vibration in phenolic group), 1634, $1605,1594 \mathrm{~cm}^{-1}$ (-phenyl ring stretching), 1511 and $1340 \mathrm{~cm}^{-1}$ ( $\mathrm{NO}_{2}$ group stretching), $1261,1224 \mathrm{~cm}^{-1}$ (C-O stretching vibrations), $1161,1188 \mathrm{~cm}^{-1} \quad(1,4$ subst. phenyl ring $\mathrm{C}-\mathrm{H}$ deformation), $995,964 \mathrm{~cm}^{-1}$ (1,2,4 subst. phenyl ring $\mathrm{C}-\mathrm{H}$ deformation), 845, 853 $\mathrm{cm}^{-1}$ (C-H aromatic out of plane deformation).

In UV-vis spectrum of the Azo-Diol in DMA solution the absorption peaks at about $551 \mathrm{~nm}$ and at about $455 \mathrm{~nm}$ are observed.

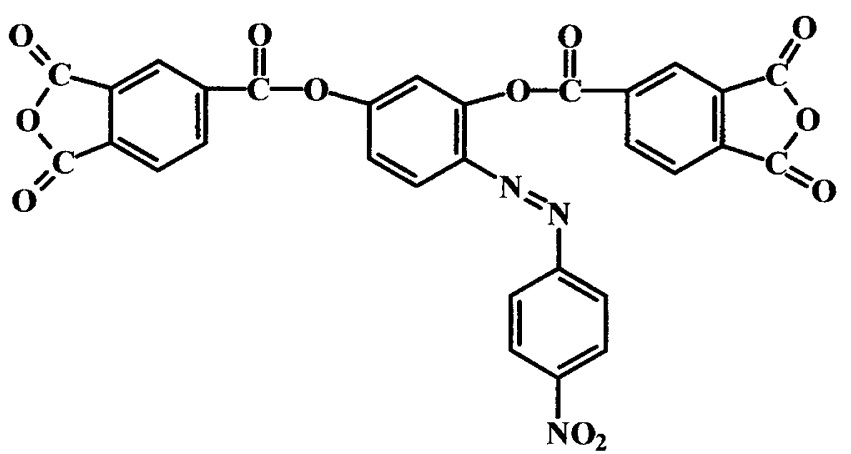

Scheme 2.

Synthesis of the Diesterdianhydride. The new diesterdianhydride with the structure (Scheme 2) was prepared as follows: in a flask equipped with a condenser, stirrer and dropping funnel, $2.2 \mathrm{mmol}$ of trimellitic anhydride acid chloride and $3 \mathrm{~mL}$ of dry acetone were placed under an argon atmosphere. The solution was heated under reflux and $1 \mathrm{mmol}$ of Azo-Diol in $3 \mathrm{~mL}$ of acetone with $2.8 \mathrm{mmol}$ of dry pyridine were added slowly over a $15 \mathrm{~min}$. The mixture was stirred and heated under reflux during $1.5 \mathrm{~h}$. After cooling to room temperature the product was filtered and dried in a vacuum oven at $50^{\circ} \mathrm{C}$ for $24 \mathrm{~h}$.

The crude product was crystallized from a mixture of acetic anhydride and acetic acid $(3: 1 \mathrm{v} / \mathrm{v})$.

Elemental analysis: found (calc.) C\%: 59.62 (59.32), $\mathrm{H} \%$ : 2.61 (2.15), N\%: 6.33 (6.92). Melting point: $207^{\circ} \mathrm{C}$ (DSC)

The structure of the dianhydride was confirmed by FT-IR (KBr): $1860,1782 \mathrm{~cm}^{-1}(\mathrm{C}=\mathrm{O}$ anhydride vibration), $1743 \mathrm{~cm}^{-1}(\mathrm{C}=\mathrm{O}$ ester group vibration), 1605 , $1487,1426 \mathrm{~cm}^{-1}$ (-phenyl ring stretching), 1523 and $1345 \mathrm{~cm}^{-1}\left(\mathrm{NO}_{2}\right.$ group stretching), $1264,1223 \mathrm{~cm}^{-1}$ (C-O stretching vibrations), $1165,1143 \mathrm{~cm}^{-1}(1,4$ subst. phenyl ring $\mathrm{C}-\mathrm{H}$ deformation), $1006,958 \mathrm{~cm}^{-1}$ $(1,2,4$ subst. phenyl ring $\mathrm{C}-\mathrm{H}$ deformation).

In UV-vis spectrum of diesterdianhydride dissolved in DMA two absorption bands were observed at about $350 \mathrm{~nm}$ and at $590 \mathrm{~nm}$.

\section{Synthesis of the Polymers}

Poly(ester-imide)s were synthesized using two-step method.

One mmol of a proper diamine was dissolved in dry DMF $(10 \mathrm{~mL})$ and $1 \mathrm{mmol}$ of a dianhydride contained azo-chromophore was added slowly during $30 \mathrm{~min}$.

The reaction was carried out at room temperature for $6 \mathrm{~h}$ under a nitrogen atmosphere. Then the mixture of pyridine and acetic anhydride $(1: 2 \mathrm{v} / \mathrm{v})$ was added into reaction solution for chemical imidization. The mixture was stirred at room temperature during $16 \mathrm{~h}$ and then was heated at $80^{\circ} \mathrm{C}$ for $1 \mathrm{~h}$. After cooling down to 
room temperature the reaction mixture was poured into vigorously stirred methanol. The precipitated polymer was filtered, washed with boiling methanol in Soxhlet apparatus and dried in a vacuum at $70^{\circ} \mathrm{C}$ overnight.

\section{Measurements of Some Physical Properties}

The glass transition temperatures and the melting points of the obtained polymers were determined with DSC 2010 TA Instrument at a heating rate of $20{ }^{\circ} \mathrm{C} \mathrm{min}{ }^{-1}$ using sealed aluminium pen (sample weight about $20 \mathrm{mg}$ ) at nitrogen atmosphere (flow rate was about $30 \mathrm{~mL} \mathrm{~min}^{-1}$ ).

For elemental analysis CHNS PerkinElmer 2400 was used.

Infrared spectra were recorded with a BIO-RAD FTS 40 A spectrometer in $\mathrm{KBr}$ pellets.

The reduced viscosity was measured in NMP at $25^{\circ} \mathrm{C}$ using an Ubbelohde viscometer. Molecular masses were determined on Finnigan MAT 95S doubly focusing instrument. Spectra were acquired in a positive-ion mode (magnetic scan).

${ }^{1} \mathrm{H}$ NMR spectra were recorded with a Varian Inova 300 Spectrometer using dimethylsulfoxide (DMSO- $d_{6}$ ) as a solvent and tetramethylsilane (TMS) as an internal reference.

Derivatograph Q-1500D MOM was used for thermogravimetric (TG) analysis (in nitrogen).

The optical transmission spectra were performed at room temperature in DMA solution with BECKMAN Acta M-IV spectrophotometer within the $200-600 \mathrm{~nm}$ range.

A deuterium lamp was a source of ultraviolet light, while tungsten lamps were used for visible and near infrared regions in this spectrophotometer.

$\mathrm{X}$-Ray diffraction measurements were performed on TUR-M62 apparatus at room temperature in the reflection mode, using Ni-filtered $\mathrm{Cu}-\mathrm{K} \alpha$ radiation. The scanning rate was over a range of $2 \theta=10^{\circ}-80^{\circ}$.

\section{RESULTS AND DISCUSSION}

New chromophore 2,4-dihydroxy-4'-nitroazobenzene was used for synthesis of functionalised polymers. The Azo-Diol was condensed with trimellitic anhydride acid chloride to give the proper dianhydride being used for condensation with various aromatic diamines. The poly(ester-imide)s have the structure shown below (Scheme 3).

The properties of the poly(ester-imide)s synthesized along with the groups -Ar-are listed in Table I.

All polymers exhibited good solubility in common organic solvents and formed bright and transparent films even though the reduced viscosities of the poly-

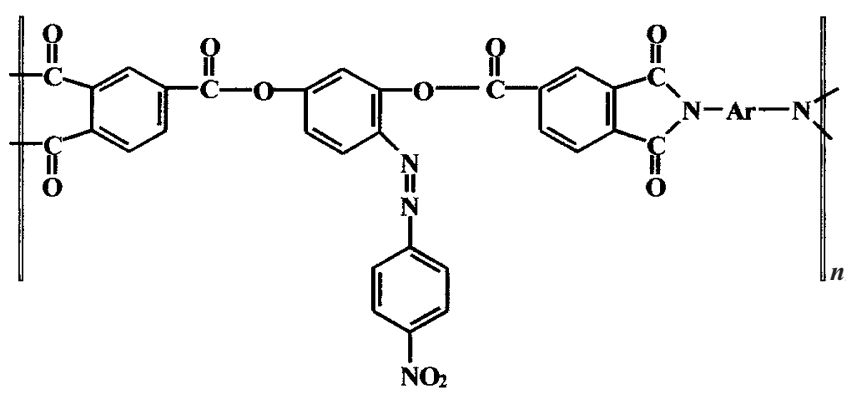

Scheme 3.

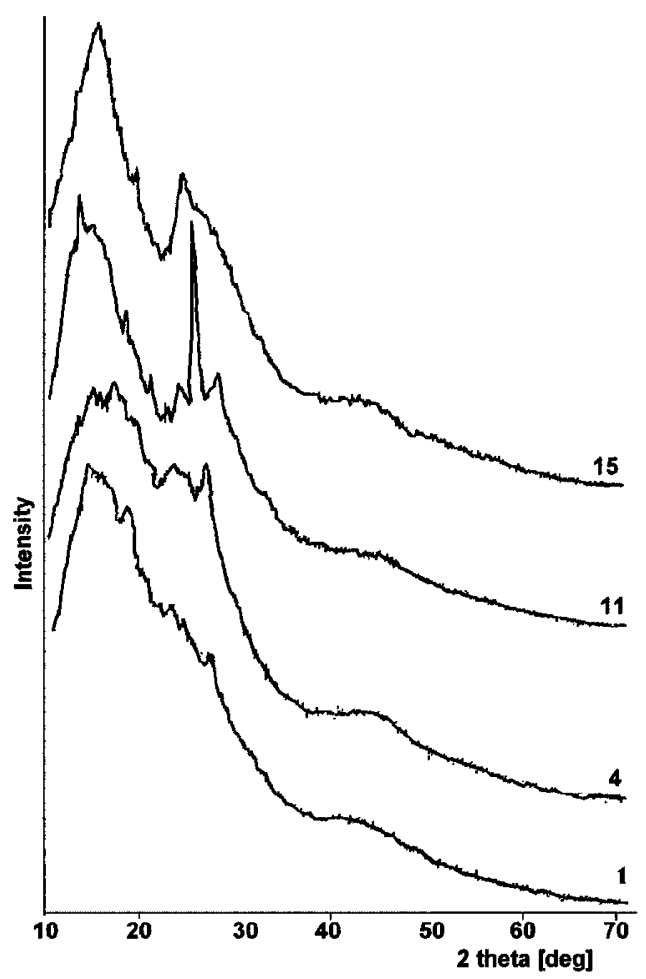

Figure 2. X-Ray diffractograms of some polymers.

mers connected with their molecular weights were low.

The X-ray diffractograms (Figure 2) confirm some ordering in the poly(ester-imide)s, being little higher in the case of the polymers synthesized from unsubstituted stiff diamines, i.e., 1,4 phenylenediamine $\mathbf{1 1}$ and benzidine $\mathbf{1 5}$. The higher crystallinity of polymers $\mathbf{1 1}$ and $\mathbf{1 5}$ was in agreement with their weaker solubility.

These polymers show good thermal resistance.

The thermal behaviour of the polymers was investigated by means of thermogravimetric analysis (TG) and differential scanning calorimetry (DSC). The thermogravimetric curves show that poly(ester-imide)s decompose under a nitrogen atmosphere in two steps. The first step is relatively fast and takes place in the range of about $250-320^{\circ} \mathrm{C}$, while the polymers loss about $5 \%$ of their weight. Then the decomposition is slow and the second step starts at about $500^{\circ} \mathrm{C}$. At $1000^{\circ} \mathrm{C}$ residue of a char is about $50 \%$.

Figure 3 shows the TG-curve obtained for the poly- 
Table I. Structures and some properties of poly(ester-imide)s

\begin{tabular}{|c|c|c|c|c|c|c|c|c|c|c|}
\hline \multirow[b]{2}{*}{ No } & \multirow[b]{2}{*}{$\begin{array}{c}\mathrm{Ar} \\
\text { (in Scheme 3) }\end{array}$} & \multirow[b]{2}{*}{$\begin{array}{c}\text { Yield } \\
{[\%]}\end{array}$} & \multirow[b]{2}{*}{$\begin{array}{c}\eta_{\mathrm{red}^{\mathrm{a}}} \\
{\left[\mathrm{dL} \mathrm{g}^{-1}\right]}\end{array}$} & \multirow[b]{2}{*}{$\begin{array}{l}\text { UV-vis } \\
\lambda_{\max }{ }^{b} \\
{[\mathrm{~nm}]}\end{array}$} & \multicolumn{3}{|c|}{$\mathrm{TG}$} & \multicolumn{3}{|c|}{$\mathrm{DSC}\left[{ }^{\circ} \mathrm{C}\right]$} \\
\hline & & & & & $\begin{array}{c}\text { Temp. of } \\
\text { beginning } \\
\text { weight loss } \\
{\left[{ }^{\circ} \mathrm{C}\right]} \\
\end{array}$ & $\begin{array}{c}\text { Temp. of } 5 \% \\
\text { weight loss } \\
{\left[{ }^{\circ} \mathrm{C}\right]}\end{array}$ & $\begin{array}{c}\text { Residual } \\
\text { weight } \\
\text { at } 1000{ }^{\circ} \mathrm{C} \\
{[\%]} \\
\end{array}$ & $T_{\mathrm{g}}$ & $T_{\mathrm{m}}$ & $\begin{array}{c}\text { Temp. start } \\
\text { of exotherm. } \\
\text { process } \\
{\left[{ }^{\circ} \mathrm{C}\right]}\end{array}$ \\
\hline 1 & & 74 & 0.19 & $\begin{array}{l}350 \\
590\end{array}$ & $\sim 270$ & 310 & 54 & 185 & 242 & $\sim 260$ \\
\hline 2 & & 86 & 0.18 & $\begin{array}{l}350 \\
590\end{array}$ & $\sim 270$ & 320 & 62 & 158 & - & $\sim 265$ \\
\hline 3 & & 80 & 0.15 & $\begin{array}{l}351 \\
590\end{array}$ & $\sim 250$ & 320 & 54 & 156 & 234 & $\sim 250$ \\
\hline 4 & & 85 & 0.18 & $\begin{array}{l}351 \\
590\end{array}$ & $\sim 255$ & 320 & 57 & 147 & 231 & $\sim 245$ \\
\hline 5 & & 34 & 0.14 & - & $\sim 230$ & 270 & 55 & 138 & 211 & $\sim 230$ \\
\hline 6 & & 81 & 0.23 & - & $\sim 260$ & 325 & 53 & 138 & 232 & $\sim 270$ \\
\hline 7 & & 89 & 0.11 & - & $\sim 220$ & 310 & 49 & 117 & 206 & $\sim 280$ \\
\hline 8 & & 87 & 0.17 & $\begin{array}{l}350 \\
590\end{array}$ & $\sim 260$ & 310 & 50 & 165 & 256 & $\sim 280$ \\
\hline 9 & & 88 & 0.98 & $\begin{array}{l}351 \\
590\end{array}$ & $\sim 280$ & 330 & 51 & 165 & 243 & $\sim 280$ \\
\hline 10 & & 85 & 0.10 & - & $\sim 260$ & 320 & 50 & 136 & 270 & $\sim 280$ \\
\hline 11 & & 86 & 0.25 & $\begin{array}{l}350 \\
591\end{array}$ & $\sim 220$ & 300 & 48 & 136 & 236 & $\sim 280$ \\
\hline 12 & & 78 & 0.31 & - & $\sim 270$ & 320 & 50 & 177 & - & $\sim 270$ \\
\hline 13 & & 81 & 0.12 & - & $\sim 250$ & 310 & 55 & 138 & - & $\sim 275$ \\
\hline 14 & & 90 & 0.12 & - & $\sim 280$ & 310 & 55 & 157 & 238 & $\sim 280$ \\
\hline 15 & & 89 & 0.28 & - & $\sim 230$ & 305 & 52 & ND & 257 & $\sim 280$ \\
\hline
\end{tabular}

${ }^{\mathrm{a}}$ Measured in NMP, conc. $=0.2 \mathrm{~g} / 100 \mathrm{~mL}$ at $25^{\circ} \mathrm{C} .{ }^{\mathrm{b}}$ Measured in DMA (anhydrous) solution $\left(\mathrm{c}=1 \times 10^{-5} \mathrm{~mol} \mathrm{~L}{ }^{-1}\right), \mathrm{ND}^{-}$not detected by DSC method.

mer 4 as an example.

In the first step the poly(ester-imide)s loss probably the nitro group of chromophore unit ${ }^{15,16}$ and the observed weight loss is in a good agreement with the content of this group in the polymer.
The temperature of the beginning of decomposition process was confirmed also by DSC measurements. On DSC-grams for all the poly(ester-imide)s investigated an exothermic process starting within the range of 240 $280^{\circ} \mathrm{C}$ was detected being probably responsible for the 


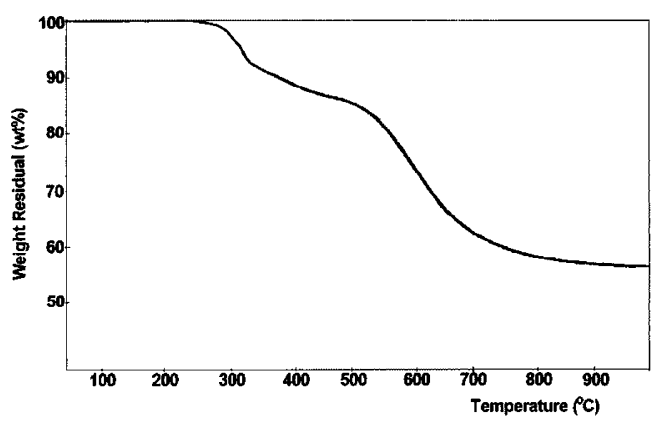

Figure 3. TG-curve of the polymer 4.

beginning of the decomposition.

The glass transition temperatures of the poly(esterimide)s were observed in the range of $117-185^{\circ} \mathrm{C}$ and are related to the diamine structure.

The polymer 1 being a product of condensation of tetramethyl substituted diaminediphenylmethane and the diesterdianhydride exhibited higher $T_{\mathrm{g}}\left(185^{\circ} \mathrm{C}\right)$ in comparison to the polymer 3 with two methyl groups $\left(T_{\mathrm{g}}=156^{\circ} \mathrm{C}\right)$ and to the polymer 4 without methyl substituents $\left(T_{\mathrm{g}}=147^{\circ} \mathrm{C}\right)$.

In the series of the poly(ester-imide)s obtained from derivatives of benzidin (4,4'-diaminebiphenyl), $T_{\mathrm{g}}$ values differed in the same way as it was detected for the polymers 1,3 , and 4 . The polymer 12 containing tetramethyl substituted biphenyl exhibited higher $T_{\mathrm{g}}\left(177^{\circ} \mathrm{C}\right)$ than dimethyl substituted one $13\left(138^{\circ} \mathrm{C}\right)$. Presence of two metoxy substituents in polymer 14 caused an increase of $T_{\mathrm{g}}$ value to $157^{\circ} \mathrm{C}$.

Similar influence of the methyl substituents at orto position to amine group on glass transition temperature of polymers was reported in ref 17,18 .

Unexpectedly, polymer $\mathbf{1 0}$ from tetramethyl-1,4phenylenediamine and from 1,4-phenylenediamine $\mathbf{1 1}$ had the same values of $T_{\mathrm{g}}\left(136^{\circ} \mathrm{C}\right)$.

The presence of two ether linkages in the diamine in the polymer 7 causes lowering of the $T_{\mathrm{g}}$ in comparison to the polymer $\mathbf{6}$ bearing one ether group.

The poly(ester-imide)s have similar degree of crystallinity as it was confirmed by X-ray diffractograms.

On DSC-grams an endothermic process due to melting of the crystalline phase was observed in the range of 206-270 ${ }^{\circ} \mathrm{C}$. But this melting process was followed by exothermic destruction reaction. Figure 4 shows DSCgram for the polymer $\mathbf{4}$ as an example.

The UV-vis spectra of poly(ester-imide)s in DMA solution (conc. $1 \times 10^{-5} \mathrm{~mol} \mathrm{~L}^{-1}$ ) exhibited two absorption bands.

The shapes of the spectra were very similar for all the polymers presented in Table I.

The main absorption peak was observed at $350 \mathrm{~nm}$ and the second at about $590 \mathrm{~nm}$ (very low intensity) and the $\lambda_{\max }$ wavelengths were almost independent of the

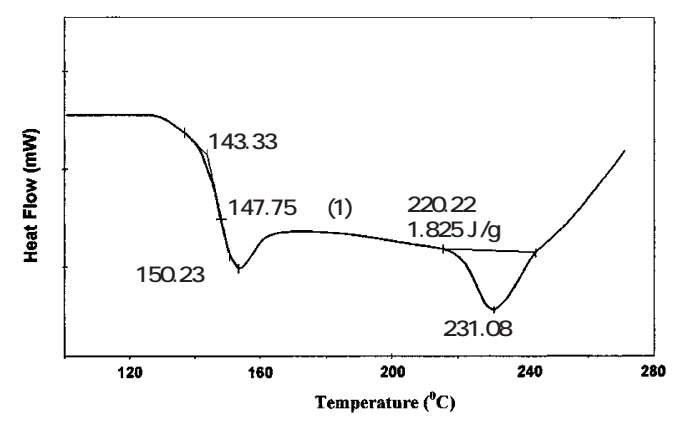

Figure 4. DSC-gram of the polymer 4.

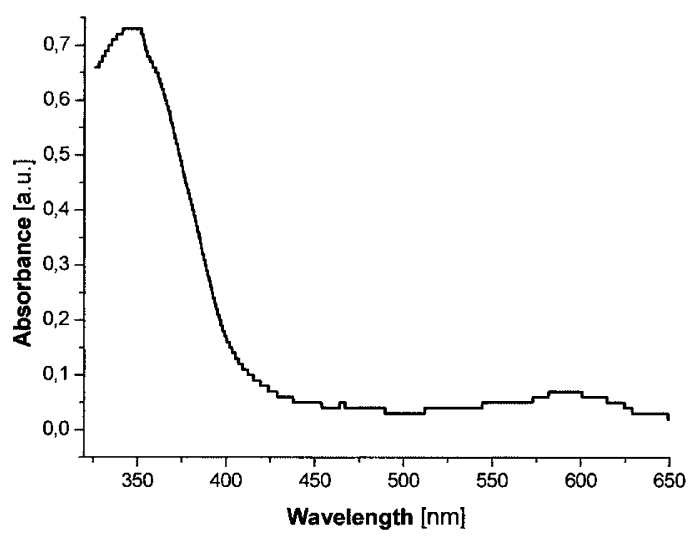

Figure 5. UV-Vis spectrum of polymer $\mathbf{1}$ as an example of absorption in DMA solution.

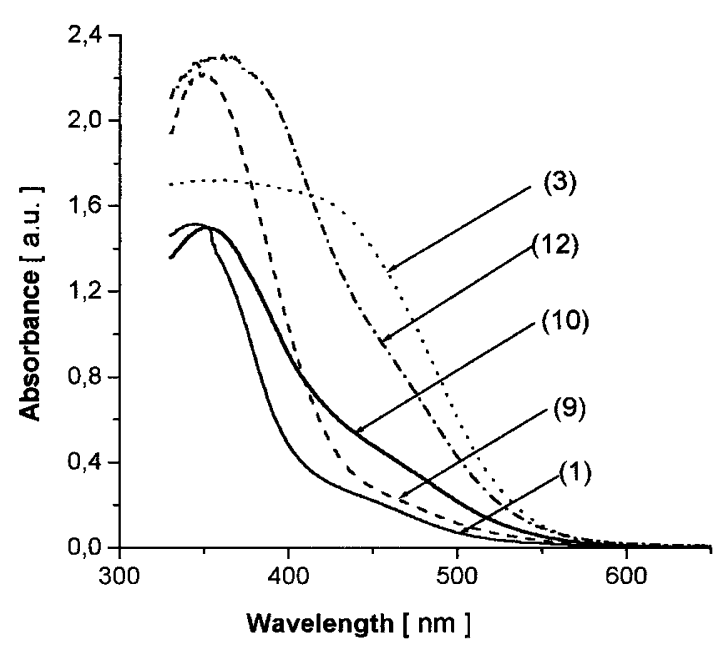

Figure 6. UV-Vis spectra of poly(esterimide) films.

polymer structures. Figure 5 shows UV-vis spectrum of the polymer 1 as example of spectra in DMA solution.

When UV-vis spectra were recorded in solid state (thin film) absorption at about $590 \mathrm{~nm}$ was not detected (Figure 6). Probably the presence of solvent enhances of $n-\pi^{*}$ transition in azo group.

The presence of the azo-groups in the synthesized polymers enables reversible photoisomerisation. Such polymeric systems form interesting class of NLO optical and photochromic materials. 


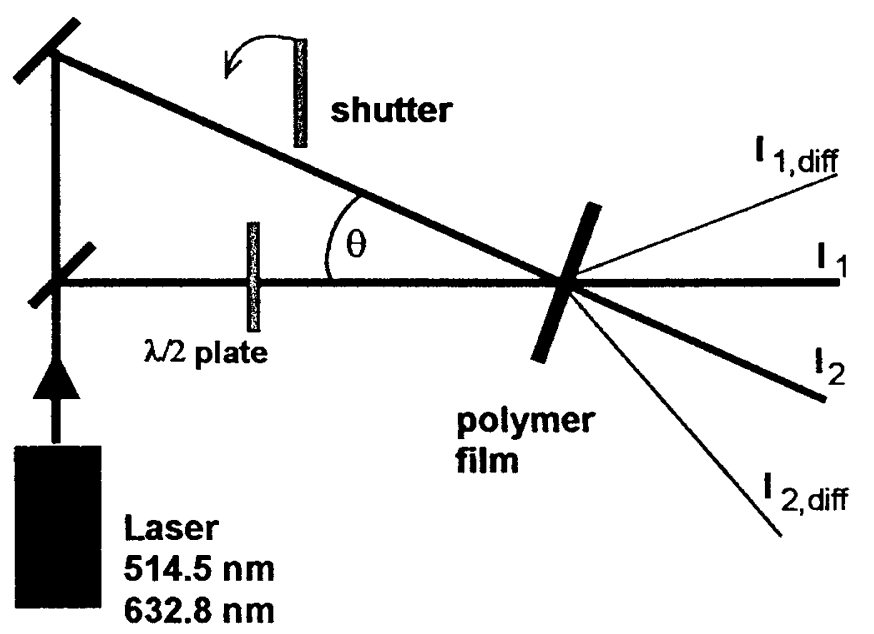

Figure 7. Experimental set-up of degenerate two-wave mixing (DTWM) using either He-Ne $(\lambda=632.8 \mathrm{~nm})$ or $\mathrm{Ar}^{+}(514.5 \mathrm{~nm})$ lasers as excitation sources. Half-wave retardation plate was used in order to perform polarisation ( $\mathrm{sp}$ ) grating recording experiments.

\section{Optical Grating Recording Experiments}

Materials containing photoresponsive chromophores are attractive in the field of optical communication and high-density optical data storage because of the reversible photoisomerisation process of azo-groups leading to photoinduced birefringence, dichroism and even mass transport. ${ }^{11-21}$ The basic mechanism responsible for the storage effect in these materials is the reorientation of azobenzene chromophores induced by light. The material ability for these purposes can be easily checked in simple experiment of degenerate twowave mixing and observation of self-diffraction process (Figure 7). When two coherent laser beams of arbitrary polarisation cross each other within optically isotropic and slightly absorbing medium, the state of polarisation of the total field changes spatially in its magnitude and orientation.

In the simplest case of the so called $s$-s polarisation (i.e., when two incoming beams $I_{1}$ and $I_{2}$ are linearly polarised with electric field vectors perpendicular to the incidence plane, VV means vertical-vertical polarisation) the phase variation between the beams produces an intensity fringe pattern of the form:

$$
I(x)=I_{0}[(1+m \cos (K x))]
$$

where, $I_{0}=I_{1}+I_{2}, m$ is the modulation factor $m=$ $2 \sqrt{I_{1} I_{2}} /\left(I_{1}+I_{2}\right)$ and $K=2 \pi / \Lambda$ is the grating wavevector. Grating spacing $\Lambda=\lambda / 2 \sin (\theta / 2)$ depends on the light wavelength $\lambda$, and an angle $\theta$ between the two inciding beams. Alternatively various polarisation grating recording geometries can be used when incident beams are orthogonally polarised ( $s-p$ or VH verticalhorizontal polarisation) or having opposite circular polarisations. ${ }^{22-26}$ The rigorous Jones matrix formalism used in the papers quoted above allows predicting of polarisations of all orders of diffraction for arbitrary polarised laser beam diffracted on such gratings. Depending on the value of Klein's parameter $Q=\frac{2 \pi \lambda d}{n \Lambda^{2}}$ gratings can be classified as thin $(Q<1)$ or thick $(Q>10)$. For the studied polymer foils of thickness $d=1.5 \mu \mathrm{m}$, $n \approx 1.6, \Lambda=3.4 \mu \mathrm{m}$ and $\lambda=0.5145 \mu \mathrm{m}$ one gets $Q=0.26$. This value suggests the Raman-Nath scattering regime, which is additionally supported by the observation of multiple diffraction orders.

In the photochromic material one expects respective "local" modulation of the complex refractive index $\Delta \hat{n}$ :

$$
\Delta \hat{n}(x)=\Delta n^{\prime}(x)+i \Delta n^{\prime \prime}(x) \propto \cos (K x)
$$

causing photoinduced anisotropy. The refractive index modulation $\Delta n^{\prime}$ and absorption modulation $\Delta n^{\prime \prime}$ occurring during the grating recording process are simultaneously intensity and time dependent. There is no simple theory describing the grating formation in a photochromic material upon a cw laser illumination due to the coexistence of phase $(\Delta \bar{n})$, amplitude $(\Delta \bar{\alpha})$ and surface relief $(\Delta \bar{d})$ gratings. ${ }^{1} \mathrm{~A}$ full theory describing light diffraction in a material with a photo-induced dichroism and birefringence including complex spatial and intensity variation of $\Delta \bar{n}$ and $\Delta \bar{\alpha}$ parameters is given in the Reference. ${ }^{23}$ In most cases (weak gratings) the diffraction efficiency defined as the ratio of the diffracted to incident beam intensity $\eta=I_{\text {diff }} / I_{\text {inc }}$ is roughly proportional to the photoinduced birefringence (and/or absorption) according to relation:

$$
\eta \propto\left(\frac{\pi \Delta n d}{\lambda}\right)^{2}
$$

The preliminary results of kinetics of holographic grating recording using $514.5 \mathrm{~nm} \mathrm{Ar}^{+}$laser light with ss-polarisation for the chosen polymers functionalised with azo-groups are presented in Figure 8 and 9. Plots of self-diffraction efficiency measured at first order diffraction versus time are given. For the comparative purposes all the experimental conditions, i.e., incident light power $\left(P_{\text {inc }}=12.5 \mathrm{~mW}\right.$ corresponding to $\left.I_{1}=I_{2} \cong 700 \mathrm{~mW} \mathrm{~cm}{ }^{-2}\right)$, intersection angle $\left(\theta=8.6^{\circ}\right)$ and recording time were kept unchanged. It seems that slightly faster recording can be obtained in polymers with lower $T_{\mathrm{g}}$ temperature. However, the differences in recording speed are not pronounced. Diffraction efficiencies are in the range $0.01-0.8 \%$ and gratings have mixed amplitude-phase character. However, we cannot rule out the possibility of surface relief grating formation and its contribution to the overall diffraction efficiency. Lacking the AFM study we can only comment that the used $s-s$ polarisation usually does not induce large surface deformations. ${ }^{1}$ 


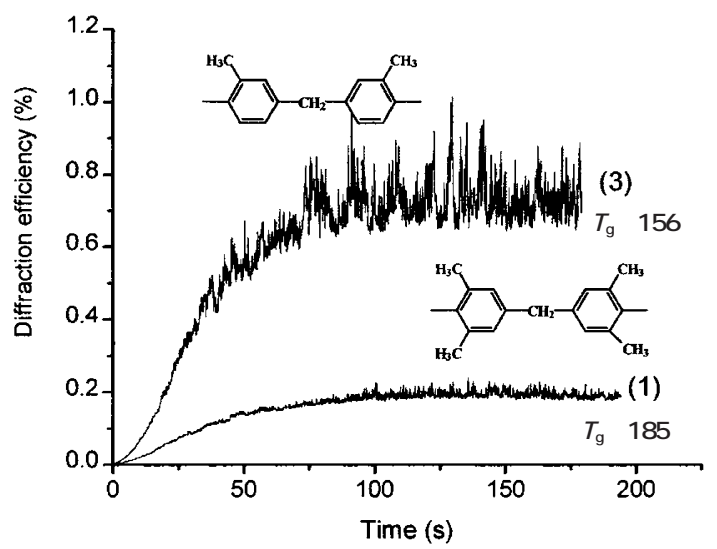

Figure 8. Plots of diffraction efficiency measured during DTWM experiment in polymers 3 and $\mathbf{1}$. The illumination power $I_{1}=12.5 \mathrm{~mW}, I_{2}=16.5 \mathrm{~mW}$, wavelength $514.5 \mathrm{~nm}$, grating period $\Lambda=3.4 \mu \mathrm{m}$.

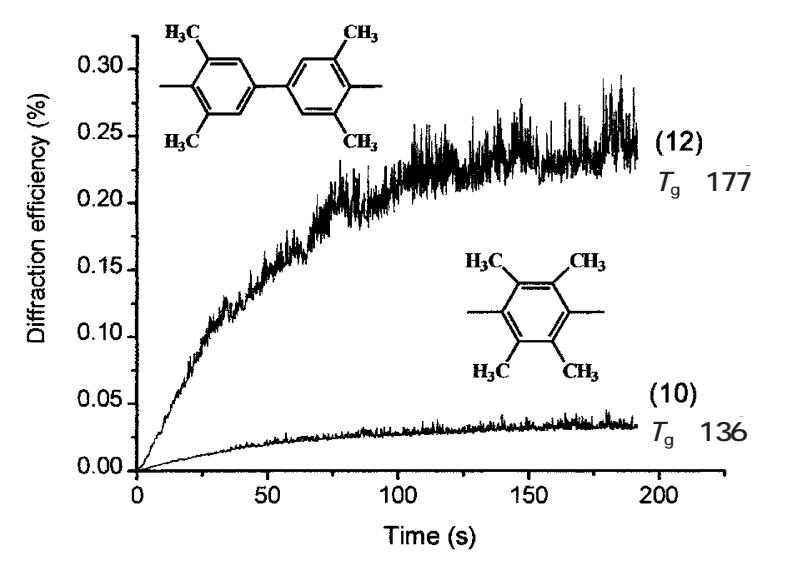

Figure 9. Plots of diffraction efficiency measured during DTWM experiment in polymers $\mathbf{1 0}$ and $\mathbf{1 2}$. The illumination power $I_{1}=12.5 \mathrm{~mW}, I_{2}=16.5 \mathrm{~mW}$, wavelength $514.5 \mathrm{~nm}$, grating period $\Lambda=3.4 \mu \mathrm{m}$.

In one of the polymers 3 we checked the intriguing property of polarisation grating recording, i.e., when two beams were orthogonally polarised with respect to each other, one $s-(\mathrm{V})$ and one $p$-polarised $(\mathrm{H}-$ horizontal). In such a case there is no associated intensity modulation at the overlapping area. Instead one observes a pure polarisation interference pattern which has the same periodicity as for $s$-s polarisation case..$^{22}$ Grating in this case will arise as a result of angular absorption selectivity by different polarisation states of the light along the grating period (linear, circular-left, linear, circular-right ${ }^{24,25}$ ) and subsequent molecular reorientations. In Figure 10 we present polarisation grating recording kinetics for polymer 3 but this time performed with weakly absorbed $\mathrm{He}-\mathrm{Ne}$ laser light of wavelength $\lambda=632.8 \mathrm{~nm}$ and the power $10 \mathrm{~mW}$. The speed of recording is much slower than for strongly absorbed $514.5 \mathrm{~nm}$ light. The plot shown in Figure 10 is a combination of $\mathrm{VH}$ recording registered by laser power meter during $63 \mathrm{~min}$, next we observed

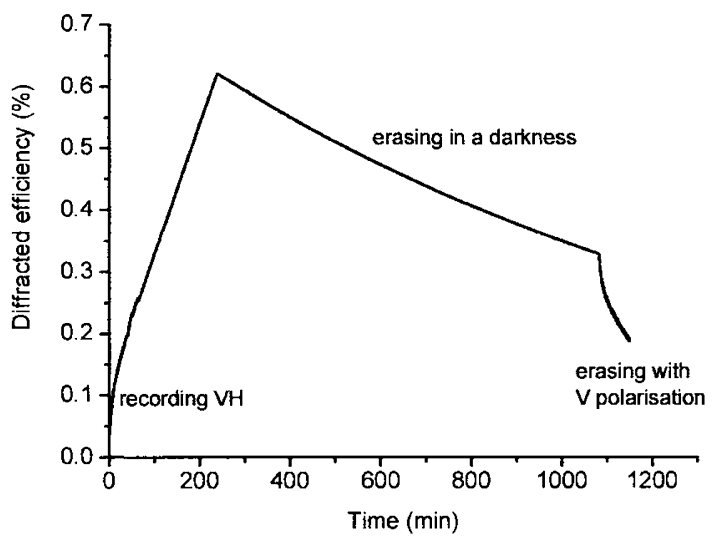

Figure 10. Polarisation grating recording experiment performed with (sp) VH orthogonal light polarisations in polymer 3. The erasing process in darkness was monitored during the night and the fast erasing with $\mathrm{V}$ polarised single beam are shown as well. The illumination powers $I_{1}=9.5 \mathrm{~mW}, I_{2}=10 \mathrm{~mW}$, beam diameters $1.5 \mathrm{~mm}$, wavelength $632.8 \mathrm{~nm}$, grating period $\Lambda=15.4 \mu \mathrm{m}$.

diffracted power at $240 \mathrm{~min}$ and switched off the laser. After $14 \mathrm{~h}$ of relaxation of the grating in the darkness we measured the kinetics of grating erasure by illuminating it with a single $s$-polarised beam. The diffraction efficiency $\eta_{\mathrm{sp}}$ for the polarisation grating in polymer $\mathbf{3}$ is higher than the diffraction efficiency $\eta_{\mathrm{ss}}$ for the intensity grating in this polymer under the same experimental conditions.

Two main mechanisms are responsible for hologram formation in polymers containing azo-groups: molecular reorientation and presence of both trans and cis isomer populations. Molecular reorientation can be regarded as arising from the combination of three consecutive processes: the angular selective trans to cis photoisomerisation, the angular diffusion and the cis to trans relaxation. Depending on the structure and viscosity of the polymer matrix (mobility of polymer chains), the relaxation times of cis molecules and orientational relaxation times, different characteristics of recording kinetics and gratings strengths in different polymers were observed. 22,24 The detailed analysis of the origin of the gratings in the investigated polymers will be our future task.

\section{CONCLUSIONS}

New photosensitive polymers - poly(ester-imide)s containing nitroazobenzene moieties as the side chain and various structures of the main chains have been synthesized.

The polymers possess good thermal stability, are soluble in aprotic solvents and exhibit film-forming properties. According to the preliminary study of optical grating recording these polymers seem to be interesting materials for optical applications. The preliminary 
investigations of the polymer 3 confirmed the ability of polarisation holographic recording in the synthesised polymers. Systematic studies of these properties are in progress.

Acknowledgments. The authors thank $\mathrm{Dr} \mathrm{B}$. Jarzạbek for UV-vis spectra measurements, Dr $\mathrm{H}$. Janeczek for DSC measurements, Dr A. Burian for WAX diffractograms recording, Ms A. Sobolewska for diffraction measurements. One of the Authors (A. M.) acknowledges financial support of Polish Scientific Committee under grant no. 4T08A 03523.

\section{REFERENCES}

1. N. K. Viswanathan, D. Y. Kim, S. Bian, J. Williams, W. Liu, L. Li, L. Samuelson, J. Kumar, and S. K. Tripathy, J. Mater. Chem., 9, 1941 (1999).

2. X. Meng, A. Natansohn, and P. Rochon, J. Polym. Sci., Part A: Polym. Chem., 34, 1461 (1996).

3. T. Buffeteau, F. Lagunge Labarthet, M. Pezolet, and C. Sourisseau, Macromolecules, 31, 7312 (1988)

4. K. Barrett, B. Choudhury, A. Natansohn, and P. Rochon, Macromolecules, 31, 4845 (1998).

5. J. A. F. Boogers, P. Th. A. Klaase, J. J. de Vlieger, and A. H. A. Tinnemans, Macromolecules, 27, 205 (1994).

6. D. H. Choi and J. H. Kim, Polym. Bull., 46, 395 (2001).

7. Z. Yuxi, L. Zhao, Q. Ling, Z. Jianfen, and Y. Peixin, Eur. Polym. J., 37, 445 (2001).

8. O. Varnavski, R. G. Ispasoiu, M. Narewal, J. Fugaro, Y. Jin, H. Pass, and T. Goodson III, Macromolecules, 33, 4061 (2000).

9. D. Sẹk, E. Schab-Balcerzak, M. Solyga, and A. Miniewicz, Synth. Met., 127, 89 (2002).
10. S. Yang, L. Li, A. L. Cholli, J. Kumar, and S. K. Tripathy, J. Macromol. Sci., Pure Appl. Chem., A38, 1345 (2001).

11. Z.-S. Xu, A. Natansohn, and P. Rochon, J. Macromol. Sci., Pure Appl. Chem., A38, 1305 (2001).

12. C. J. L. Constantino, R. F. Aroca, S. Yang, V. Zucolotto, L. Li, O. N. Oliveira, Jr., A. L. Cholli, J. Kumar, and S. K. Tripathy, J. Macromol. Sci., Pure Appl. Chem., A38, 1549 (2001).

13. S. Yokoyama, M. A. Kakimoto, and Y. Imai, Langmuir, 9, 1086 (1993).

14. S. Yokoyama, T. Yamada, K. Kajikawa, M. Kakimoto, Y. Imai, H. Takezoe, and A. Fukuda, Langmuir, 10, 4599 (1994).

15. C. Jung, T. Aoyama, T. Wada, H. Sasabe, M. Jikei, and M. Kakimoto, High Perform. Polym., 12, 205 (2000).

16. M. Ahlheim and F. Lehr, Macromol. Chem. Phys., 195, 361 (1994).

17. G. C. Eastmond and J. Paprotny, React. Funct. Polym., 30, 27 (1996).

18. G. C. Eastmond, J. Paprotny, and I. Webster, Polymer, 13, 2865 (1993).

19. T. Todorov, L. Nikolova, and N. Tomova, Appl. Opt., 23, 4309 (1984).

20. Z. Sekkat, D. Morichere, M. Dumont, R. Loucif-Saibi, and J. Delaire, J. Appl. Phys., 71, 1543 (1992).

21. P. Lefin, C. Fiorini, and J.-M. Nunzi, Opt. Mater., 9, 323 (1998).

22. J. Tervo and J. Turunen, Opt. Commun., 190, 51 (2001).

23. T. Huang and K. H. Wagner, J. Opt. Soc. Am., B13, 282 (1996).

24. P.-A. Blanche, Ph.C. Lemaire, C. Maertens, P. Dubois, and R. Jerome, Opt. Commun., 185, 1 (2000).

25. G. Cipparrone and A. Mazzulla, J. Opt. Soc. Am., B19, 1157 (2002).

26. I. Naydenova, L. Nikolova, T. Todorov, N. C. R. Holme, S. Hvilsted, and P. S. Ramanujam, J. Opt. Soc. Am., B15, 1257 (1998). 